\title{
DEL CONTROL SOCIAL A LA POLITICA SOCIAL La conflictiva relación entre los jóvenes populares y el Estado en la historia de Chile
}

\author{
IGOR GOICOVIC DoNOSO*
}

\section{Presentación}

NO CABE DUDA QUE el Estado sólo en períodos muy recientes ha asumido como responsabilidad pública los problemas y demandas del mundo popular. Pero al hacerlo no se ha mostrado interesado en observar e intervenir sobre los problemas estructurales y de largo aliento sino que básicamente ha pretendido actuar sobre las situaciones de coyuntura y por lo tanto en la superficie de la problemática social. De ahí que la política social carezca en general de sentido y contenido estratégico, capaces de darle estabilidad a las relaciones sociales y al sistema político. Los peligrosos avatares de la sociedad chilena durante el siglo XX son la demostración más contundente de dicha situación.

El objetivo de esta reflexión es reivindicar la ciencia histórica en una doble dimensión del conocimiento: por una parte, comprender por qué el Estado en Chile ha desarrollado determinadas políticas públicas, en qué contexto de más larga duración se inscriben y cuáles son las relaciones de poder que orientan su construcción; y, por otro lado, asumir una opción epistemológica que revele las potencialidades

* Investigador CIDPA, Docente Departamento de Historia, Universidad de Santiago de Chile. 
existentes en el colectivo social popular en cuanto productor de cultura y por ende como constructor de sociedad.

Los jóvenes, como sujetos del proceso histórico —por ende como constructores de sociedad-y como categoría del análisis social, son un hallazgo reciente. Tanto en el Chile colonial como en el Estado republicano, la juventud, y particularmente la juventud popular, careció de identidad propia. Su dimensión ontológica (ser) y su intervención histórica (quehacer) se diluía al interior de las clases sociales subordinadas. Carecía de especificidad en cuanto grupo social. Ello porque en el Chile tradicional se era pobre y excluido antes, durante y después de ser joven. Es por lo anterior que la historia social en Chile asumió como objeto preferente de estudio a las clases populares en su conjunto (desde los clásicos estudios de Hernán Ramírez Necochea, Julio César Jobet y Jorge Barría, hasta los más recientes de Gabriel Salazar, Julio Pinto y Sergio Grez ${ }^{1}$ ) o, con menos énfasis, se ha preocupado de los estudios de género (Alejandra Brito y Margarita Iglesias, entre otras ${ }^{2}$ ) y sobre los problemas de la infancia popular (Jorge Rojas y Nicolás Corvalán ${ }^{3}$ ). Pero los jóvenes no han convocado el interés de los historiadores ni en general ni en particular.

1 Hernán Ramírez Necochea: Historia del movimiento obrero en Chile. Antecedentes siglo XIX, Editorial Austral, Santiago, 1956. Julio César Jobet: Ensayo crítico del desarrollo económico-social de Chile, Editorial Universitaria, Santiago, 1955. Jorge Barría Serón: El movimiento obrero en Chile. Síntesis histórico-social, Ediciones de la Universidad Técnica del Estado, Santiago, 1972. Gabriel Salazar: Labradores, peones y proletarios. Formación y crisis de la sociedad popular chilena del siglo XIX, Ediciones SUR, Santiago, 1990. Julio Pinto — de entre una vasta producción de artículos-, «Donde se alberga la revolución. La crisis salitrera y la propagación del socialismo obrero, (1920-1923)», Contribuciones Científicas y Tecnológicas N¹22, 1999. Sergio Grez: De la 'regeneración del pueblo' a la huelga general. Génesis y evolución histórica del movimiento popular en Chile (1810-1890), DIBAM, Santiago, 1997.

2 Alejandra Brito: «La construcción histórica de las mentalidades de género en la sociedad popular chilena, 1900-1930», Nomadías. Monográficas N¹, Santiago, 1999. Margarita Iglesias: «Funcionamiento de la estructura matrimonial y el comportamiento de algunas mujeres en el siglo XVIII», en Descorriendo el velo. Actas de las II y III Jornadas de Investigación en Historia de la Mujer, Santiago, 1998.

3 Nicolás Corvalán Pino: «Amores, intereses y violencias en la familia de Chile tradicional. Una mirada histórica a la cultura afectiva de niños y jóvenes», Contribuciones Científicas y Tecnológicas №114, 1996. Jorge Rojas Flores: Los niños cristaleros: trabajo infantil de la industria. Chile, 18801950, DIBAM, Santiago, 1996. 
Cómo se explica esta situación. Una primera aproximación tiene que ver - como lo señalamos previamente- con lo reciente de la preocupación de la política social por el sector juvenil y, efectuando una mirada de más largo aliento, con lo novedoso que es encontrar política social para todos los consumos sectoriales. Efectivamente, esta incorporación del Estado al debate sobre los problemas de la sociedad, independiente de la óptica o de los contenidos que la orientan, es también muy reciente en la historia de Chile. Se puede aseverar, sin temor a equivocarnos, que tiene una data inferior a los 100 años. Así, por ejemplo, la política social a comienzos del siglo XX tiene su origen en las movilizaciones populares, especialmente del movimiento obrero, que, al cuestionar la estabilidad del régimen de dominación, hicieron necesaria su elaboración y posterior aplicación. ${ }^{4}$ Algo similar ocurre con la política pública de vivienda a partir de la década de 1920, la que nace de las huelgas de arrendatarios de ese período y se consolida con las tomas de terrenos de la las décadas de 1960 y $1970 .^{5}$ No escapa a esta tendencia la legislación social agraria de la década de 1960, la cual se explica en buena medida por la agitación política que se vive en los campos de Chile desde comienzos de la década de 1950.6

En consecuencia, buscar en la historia la presencia de los jóvenes constituye un ejercicio complejo, para el cual las fuentes oficiales no son precisamente muy pertinentes. Es por ello que debemos escarbar en los intersticios de las fuentes, en aquello que no dicen, aquello que dicen entrelíneas o incluso en aquello que ocultan, a objeto de encontrar a los jóvenes e identificar su presencia en el escenario social.

Aproximarnos a ellos nos obliga a tomar en cuenta aquellas fuentes que se hacen cargo de los sectores populares y de sus problemas, específicamente: los archivos notariales, judiciales y eclesiásticos, los bandos de buen gobierno o los informes de autoridades loca-

4 Jorge Barría Serón: Los movimientos sociales en Chile desde 1910 hasta 1926 (aspecto político y social), Editorial Universitaria, Santiago, 1960. Crisóstomo Pizarro: La huelga obrera en Chile, 1890-1970, Ediciones SUR, Santiago, 1986.

5 Vicente Espinoza: Para una historia de los pobres de la ciudad, Ediciones SUR, Santiago, 1988.

6 Almino Affonso et al.: Movimiento campesino chileno, ICIRA, Santiago, 1970. Sergio Gómez: «El movimiento campesino en Chile», FLACSO, Documento de Trabajo №246, Santiago, 1985. 
les, los padrones de población, la prensa, etc. En estas fuentes la mano minuciosa del escribano, del funcionario público o del periodista registraba con dedicación - de acuerdo con las funciones que les eran propias-, el nombre, sexo, estado civil, origen espacial y social y edad de los comparecientes, o el oficio y la conducta desplegada por los sujetos. De esta manera es posible desentrañar las pisadas pretéritas de nuestros jóvenes, reconocer sus quehaceres, auscultar sus visiones de mundo y adentrarnos en sus quehaceres. Trataremos entonces de recrear algunos aspectos de ese peregrinar.

\section{REBELDÍAS Y DISCIPLINAMIENTO}

Históricamente los jóvenes han sido un grupo social discriminado y excluido. Su transitar por la escena nacional ha discurrido entre su integración forzada a las relaciones laborales impuestas por las élites dominantes y el acoso permanente que sobre ellos ha ejercido el Estado. Hace cien, cincuenta o treinta años atrás, ser joven en Chile tenía una connotación absolutamente diferente a la que conocemos hoy día. Así, durante el siglo XIX los jóvenes constituyeron mayoritariamente esa amplía masa laboral de peones-gañanes que deambulaban de un lugar a otro en busca de un empleo precario. ${ }^{7}$ Mientras que a mediados de la presente centuria los jóvenes populares difícilmente concluían su enseñanza básica y con los primeros rudimentos de la lecto-escritura y la aritmética, debían salir al mercado laboral a ofertar su fuerza de trabajo. ${ }^{8}$ Se trata de un período en el cual los jóvenes populares, con sólo 13 ó 15 años, comenzaban rápidamente a realizar el proceso de aprendizaje laboral que debían conducir a su proletarización. La fábrica, el campamento minero o la faena agrícola, se transformaban en los ámbitos de sociabilización por excelencia para quienes, a muy temprana edad, debían abandonar sus hogares y buscar el sustento con sus propias manos. No existía la adolescencia. De la infancia se transitaba a la adultez de manera brusca y vertiginosa. ${ }^{9}$

7 En relación con la construcción social del peonaje, ver, Gabriel Salazar: Labradores, peones y proletarios. Formación y crisis de la sociedad popular chilena del siglo XIX, Ediciones SUR, Santiago, 1990.

8 Al respecto ver de María Angélica Illanes: 'Ausente señorita'. El niño chileno, la escuela para pobres y el auxilio. Chile, 1890-1990, JUNAEB, Santiago, 1991.

9 Luis Vildósola: «A los 14 años mi papá ya sentía que era un hombre. El sujeto popular de Viña del Mar durante la primera mitad del siglo XX», Úl- 
Esta transición se veía tempranamente apurada en aquellos hogares populares en los cuales la cohesión interna del grupo familiar era poco consistente. La inestabilidad generada por los diferentes ciclos económicos, la dispersión de los mercados de trabajo, los débiles niveles de especialización de la mano de obra popular, obligaba a los jefes de hogar a desplazarse permanentemente en busca de mejores condiciones salariales o laborales. Lo anterior redundaba en la masificación del problema social denominado «padre ausente». El abandono del hogar por parte de la figura masculina no sólo generaba un importante impacto sicológico en los hijos abandonados, implicaba, además, que la madre debía asumir crecientes roles en la diaria lucha por la subsistencia familiar. Empresa que no sólo desgastaba sus fuerzas físicas sino que además desembocaba en el cuestionamiento social de su idoneidad moral. Señalada con el dedo social como: «chinganera», «fritanguera», «prostituta» o «mal avenida», la mujer popular en Chile debía sostener a su grupo familiar y orientar su subsistencia y, además, defender su honor público. Lo anterior exigía el concurso de todos aquellos que estuvieran en condiciones de aportar a la estrategia de subsistencia colectiva. ${ }^{10}$ Esto obligaba a muchos jóvenes a seguir tempranamente las huellas de sus padres y «echarse a andar», a objeto de recabar sus propios recursos. ${ }^{11}$

tima Década N³, Ediciones CIDPA, Viña del Mar, 1995.

10 Estos temas los hemos tratado ampliamente en otras publicaciones, «Labrando la tierra, sirviendo la casa. El trabajo infantil en Chile tradicional», Actas del Seminario Internacional, Cambios y continuidades en los comportamientos demográficos en América: la experiencia de cinco siglos, IUSSP, Universidad de Córdoba, Córdoba, Argentina; «Prestación de servicios personales y relaciones de reciprocidad en el mundo femenino del Chile tradicional. Illapel, 1750-1850», en Descorriendo el velo...; «Mujer, trabajo y reproducción social en el Chile decimonónico. Mincha, 1854», Nomadías, Monográficos $\mathrm{N}^{\circ} 1,1999$.

11 A diferencia de lo que ocurría en las economías agrarias y mineras precapitalistas de América Latina, en la Europa del siglo XIX, en pleno proceso de expansión industrial, el objetivo prioritario de los jóvenes era contraer matrimonio y establecerse. Ello debido a que sólo la formación de una nueva pareja les garantizaba la posibilidad de marcharse de la casa familiar y por lo tanto de independizarse, tanto desde el punto de vista afectivo como del económico. En Europa, las familias populares intentaban retrasar lo más posible la salida de los hijos, por cuanto cada uno de ellos se constituía, normalmente, en un engranaje del proceso fabril y, con ello, en un soporte de la subsistencia colectiva. Al respecto ver, Michelle Perrot: «La juventud obrera. Del taller a la fábrica», en Giovanni Levi y Jean-Claude Schmitt (direc- 
Lo anterior explica el temprano abandono del hogar por parte de muchos jóvenes populares. Así la rápida desintegración de sus grupos familiares y las crecientes necesidades de encontrar nuevos recursos para la subsistencia, expulsaban a muchos jóvenes al mercado laboral. No es menos efectivo, además, que desde comienzos del siglo XX, con el sostenido desarrollo de la industria nacional, el mercado laboral requirió del concurso permanente de nuevos contingentes de mano de obra. Fenómeno que convirtió en extraordinariamente atractivo este rubro. Pero esta inserción laboral y social no fue un proceso fácil. La situación desmedrada en que ella se realizaba, empujaba a muchos jóvenes populares a resistir los procesos de proletarización y, con ello, a ser objeto de las más denodadas presiones estatales. ${ }^{12}$

En este contexto las formas de asociatividad desplegadas por los jóvenes se caracterizaban por su alto nivel de flexibilidad organizativa, se trataba de «gavillas», «bandas de mendigos y vagabundos», "grupos de malentretenidos», o sencillamente «bandidos», etc. ${ }^{13}$ Es decir, estamos frente a un proceso de asociatividad primario, en el cual la actitud de resistencia frente a las compulsiones devenidas del sistema, se convierten en el rasgo aglutinador por excelencia. Desde estas instancias los jóvenes populares despliegan toda una red de mecanismos de subsistencia, desde aquellos que deslindan en la delincuencia (salteadores, cuatreros y ladrones) hasta aquellas funciones laborales que los integran en el sistema capitalista (peones y proletarios), pasando por las que los sitúan en los bordes del mismo (pulpe-

tores): Historia de los jóvenes. II La Edad Contemporánea, Taurus, Madrid, pp.119-125.

12 El tema de la proletarización de las relaciones laborales y su impacto social y cultural han sido ampliamente desarrollados por Julio Pinto: «Cortar raíces, criar fama. El peonaje chileno en la fase inicial del ciclo salitrero (1850-1879)», Historia N³0, 1997; «La caldera del desierto. Los trabajadores del guano y los inicios de la cuestión social», Proposiciones Nº19, 1990; «La transición laboral en el norte salitrero: la provincia de Tarapacá y los orígenes del proletariado en Chile, 1870-1890», Historia №25, 1990.

13 Es interesante observar que en este mismo período en Europa, los jóvenes populares convirtieron a la «pandilla» en la forma de asociatividad más recurrente. Estas asociaciones, espontáneas y escasamente jerarquizadas, se convirtieron en el crisol de una intensa sociabilidad juvenil, que despertaba los temores de las clases dominantes. Michelle Perrot: Op. cit., pp.105 y 142-143. 
ras, fritangueras, chinganeras, trabajadores de oficios varios, etc.). ${ }^{14}$

Frente a esta conducta social, eminentemente popular y con alto grado de participación juvenil, el Estado desplegó una serie de medidas destinadas a encuadrar el accionar social y laboral de los jóvenes populares en el contexto de los requerimientos del orden capitalista. Disciplinar al mundo popular pasaba por legitimar al interior del «bajo pueblo» la modalidad capitalista de relaciones laborales -imponer el salariado-, lo cual comenzó a operar con particular dinamismo en las faenas salitreras del Norte Grande, a las que se sumó posteriormente la moderna actividad industrial. ${ }^{15}$ Se trataba, además, de reglamentar y limitar todas aquellas actividades económicas y sociales que pusieran en riesgo la estabilidad del sistema capitalista o que facilitaran el desarrollo de la autonomía empresarial popular. ${ }^{16}$

También había que hacer presente — discursivamente — a los sectores populares que sus conductas conspiraban contra el adecuado desarrollo de la «nación». De ahí deviene el discurso moralizador que, sustentado principalmente por la Iglesia Católica, por la educación pública y por la prensa de la época, apuntaba a denunciar y execrar el impacto que las conductas «desarregladas» tenían en la sociedad. ${ }^{17}$

14 La transgresión social y las formas de asociatividad popular orientadas a la transgresión han sido escasamente tratada por la historiografía tradicional. Una excelente aproximación a este tema, para el ámbito rural, se encuentra en el trabajo de Jaime Valenzuela: Bandidaje rural en el Chile central. $\mathrm{Cu}$ ricó, 1850-1900, DIBAM, Santiago, 1991. Para el mundo urbano los trabajos de Luis Alberto Romero, recopilados en el libro, ¿Qué hacer con los pobres? Élites y sectores populares en Santiago de Chile, 1840-1895, Sudamericana, Buenos Aires, 1997, son de consulta obligatoria.

15 La proletarización de la mano de obra en las faenas salitreras se encuentra tratada en los trabajos de Julio Pinto previamente citados. Similar proceso en el ámbito industrial se puede analizar en los estudios de Hernán Ramírez Necochea, Jorge Barría Serón y Crisóstomo Pizarro, también citados previamente.

16 Un trabajo pionero en el análisis de la empresarialidad popular y de los conflictos que ésta tuvo con el Estado, se puede encontrar en el artículo de Gabriel Salazar: «Empresariado popular e industrialización: la guerrilla de los mercaderes (Chile, 1830-1885)», Proposiciones №20, 1991.

17 Al respecto resulta particularmente interesante revisar los artículos de la Revista Católica o de la prensa conservadora (El Diario Ilustrado o El Estandarte Católico), que a fines del siglo XIX y comienzos del Xx, difundían profusamente normas y valores asentados en una ética y una moral intimista y conservadora. La versión laica de este fenómeno, y especialmente el discurso modernizador del Estado como mecanismo de estructuración y legitimación del orden social, ha sido estudiada por Claudio Barrientos y Nico- 
Por último había que establecer duras sanciones contra toda manifestación de rebeldía organizada que cuestionara las bases sociales y políticas del sistema; de esta manera, a la represiones masivas dirigidas contra los obreros salitreros, los mapuches y los campesinos alzados en armas, se sumó el Servicio Militar Obligatorio y la introducción, a partir de 1924, de una prolífica legislación social que apuntaba a encuadrar el accionar de los sectores populares en el marco de la institucionalidad capitalista, proceso que encuentra su culminación con la dictación del Código del Trabajo en $1931 .{ }^{18}$ Se impone de esta manera en el debate interoligárquico la «cuestión social».

Éste es, precisamente, el período en el cual se produce la exaltación del control social sobre la sociedad y los jóvenes populares. No existe política social. La tarea del Estado es asegurar el ejercicio del poder oligárquico, de ahí que sus tareas fundamentales se orienten a perseguir y encuadrar toda forma de transgresión. En subsidio, las preocupaciones por las condiciones de vida de los sectores populares quedaban relegadas al ámbito de intervención de la Iglesia o a la autogestión de los propios trabajadores. La caridad y el mutualismo se convirtieron, entonces, en la vía de solución a parte de los problemas del mundo popular. ${ }^{19}$

lás Corvalán en su artículo: «El justo deseo de asegurar el porvenir moral y material de los jóvenes. Control y castigo en las prácticas educativas de la Escuela de Artes y Oficios», Última Década Nº6, 1997.

18 Las masacres llevadas a cabo contra los sectores populares por parte de los aparatos represivos del Estado se encuentran descritas de manera general en la historiografía «obrerista» (Jobet, Ramírez Necochea, Barría); más recientemente se han comenzado a investigar en profundidad algunos episodios específicos; Eduardo Devés: Los que van a morir te saludan. Historia de una masacre. Escuela Santa María de Iquique, 1907, Ediciones Documentas, Santiago, 1989. Rolando Álvarez Vallejos: «La matanza de La Coruña», Contribuciones Científicas y Tecnológicas №116, 1997. Igor Goicovic Donoso: «Surco de sangre, semilla de redención. La revuelta campesina de La Tranquilla (1923)», Valles. Revista de Estudios Regionales №3, 1997. El impacto político de la legislación laboral que dio origen al Código del Trabajo de 1931 ha sido analizado por Jorge Rojas Flores en su libro: La dictadura de Ibáñez y los sindicatos (1927-1931), DIBAM, Santiago, 1993; mientras que las proyecciones más amplias de este fenómeno fueron analizadas exhaustivamente por Alan Angell: Partidos políticos y movimiento obrero en Chile, Era, México, 1974 y Paul Drake: Socialismo y populismo. Chile, 1936-1973, Universidad Católica de Valparaíso, Valparaíso, 1992.

19 Las sociedades mutualistas laicas han sido estudiadas por Sergio Grez Toso: Op. cit. y por María Angélica Illanes: La revolución solidaria. Historia de las sociedades obreras de socorros mutuos. Chile, 1840-1920, Colectivo de 
A contrapelo de los pálidos intentos por morigerar el enfrentameinto social, la eclosión de las medidas punitivas y disciplinadoras desplegadas por el Estado con las conductas de resistencia originadas en el mundo popular, dieron origen a un ethos cultural obrero y popular de profunda trascendencia y raigambre en la historia contemporánea de Chile. Ethos cultural del cual los jóvenes populares fueron principales depositarios y protagonistas.

\section{JÓVENES Y ESTADO. ENTRE LA INTEGRACIÓN COOPTADA Y LA AUTONOMÍA CULTURAL}

Es nuestra percepción que el mundo juvenil popular se encuentra, por lo menos hasta fines de la década de 1950, integrado en el mundo adulto. En esta época, tanto la demanda juvenil corporativa, como el quehacer social juvenil, se desenvuelve al interior e integrado, a la demanda sectorial de las asociaciones adultas - sindicatos, partidos políticos populares, etc.- - Como señala Michelle Perrot, al estudiar la situación de los jóvenes en Europa durante el siglo XIX,

Los jóvenes obreros no gozaban, como los jóvenes burgueses de ese tiempo, de latencia y de formación que autoriza una sociabilidad propia y eventualmente una expresión autónoma. ${ }^{20}$

En este punto cabe hacer una clara distinción con los sectores juveniles de la élite o de los estratos medios de la sociedad, los cuales tienden a conformar un sector perfectamente diferenciado, e incluso constituido en movimiento, a través de su participación en la instancias de asociación corporativa que prestan los planteles de estudios secundarios y universitarios. Lo anterior como una suerte de escuela de formación para acceder, especialmente en el caso de las llamadas profesiones liberales, al estrecho circuito de la política —adulta—. ${ }^{21}$

Atención Primaria, Santiago, 1990. Las sociedades católicas sólo en estos últimos años han comenzado a llamar la atención de los historiadores. Al respecto cabe citar la tesis de licenciatura de Hernán Nuñez y Jaime Vivanco: «El trabajador católico, sus organizaciones laborales y la relación con su iglesia, 1860-1927», Universidad de Chile, Facultad de Humanidades, Departamento de Historia, Santiago, 1988.

20 Michelle Perrot: Op. cit., p.104.

21 Con el ascenso al gobierno de Arturo Alessandri Palma en 1920, se modificó de manera importante el quehacer político nacional. Las capas medias de la población, hasta ese momento sistemáticamente excluidas del ejercicio 
Pero nosotros queremos referirnos específicamente a un sector social y no exclusivamente generacional, diametralmente distinto: el joven popular, aquel que, hasta la fecha antes indicada, carece de visibilidad en cuanto a tal respecto de los «otros» (Estado y sociedad). Ello debido a que los jóvenes no existían en cuanto sujetos sociales, a excepción de cuando el tránsito de la infancia a la adultez quedaba jalonado por la ejecución de una conducta transgresora -mendigos, gavilleros, etc.- - Es más, ni siquiera afloran en el plano de la estigmatización —algo tan común hoy día-, ya que ésta recae sobre el conjunto de los sectores populares, sin distinción de edades, de sexo o de grupo étnico.

Es por ello que la política social se orienta desde comienzos del siglo XX al conjunto de los sectores populares, sin establecer distinciones sectoriales entre ellos. Lo anterior se explica en gran medida por la carencia - a lo menos durante las tres primeras décadas del siglo- de un modelo teórico general que permitiera abordar coherentemente el problema de la pobreza. Pese a lo anterior no cabe duda que, especialmente desde la década de 1930 en adelante, se comenzó a manifestar una clara tendencia hacia una mayor justicia social, fenómeno que se tradujo en un creciente desarrollo social. Los pobres y sus problemas comenzaron a ocupar un lugar importante en la agenda política de los gobiernos de la época. ${ }^{22}$

Los hitos más importantes en esta primera fase del proceso fueron la Ley sobre Enseñanza Primaria Obligatoria (1920), el Código del Trabajo (1931), la creación de la Caja de Habitación Popular (1936), el Servicio Nacional de Salud (1952) y la Junta Nacional de Auxilio Escolar y Becas (1953). Ellos ponen de manifiesto que las principales disposiciones tomadas por las autoridades se centraron en la regulación de las relaciones laborales, las condiciones de trabajo y las remuneraciones de los trabajadores y en la satisfacción de las nece-

del poder, comenzaron a ocupar el aparato del Estado y desde él se constituyeron y reprodujeron como clase política. Las décadas comprendidas entre 1930 y 1970 vieron surgir en el escenario público a una amplia pléyade de dirigentes políticos mesocráticos —Eduardo Frei Montalva, Salvador Allende Gossens, Rafael Agustín Gumucio, etc.-, que hicieron sus primeras armas políticas en los claustros universitarios. En esta últimas década varias decenas de «memorias» y «biografías» relativas a estos personajes nos describen los ámbitos en los cuales se sociabilizaron (políticamente) y los procesos que les tocó protagonizar.

22 Mariana Paz Schkolnik y Luis Eduardo Riquelme: Evolución de las políticas sociales 1920-1991, MIDEPLAN, Santiago, 1991, p.4. 
sidades de educación, salud, nutrición, vivienda y seguridad social. ${ }^{23}$

La llegada al gobierno de la Democracia Cristiana, en 1964, marcó el comienzo de un sistemático proceso de redistribución del ingreso. El programa social del Gobierno de Eduardo Frei Montalva, claramente influido por las ideas del sacerdote jesuita Roger Vekemans, se planteó la política de "promoción popular» como estrategia para erradicar la marginación social y, por ende, como paso imprescindible para la erradicar la pobreza. ${ }^{24}$ Es así como se ampliaron los beneficios sociales para los sectores populares, especialmente para campesinos y pobladores, y se comenzaron a ejecutar una serie de iniciativas que modificaron la estructura de la propiedad de la tierra (Reforma Agraria) y el acceso y construcción del espacio urbano (operación sitio). ${ }^{25}$

Es precisamente en este momento cuando la situación de invisibilidad del mundo juvenil comienza a revertirse. Efectivamente, concurren, a mediados de la década de 1960, situaciones estructurales que afectan de manera importante a los estratos más jóvenes de la población, como la expansión experimentada por los procesos de escolarización, especialmente primarios y secundarios, la ampliación del horizonte cultural urbano a través de los procesos de migración campo-ciudad y la radicalización de los procesos políticos y sociales, en los cuales le compete al movimiento estudiantil —particularmente universitario- un rol protagónico. ${ }^{26}$

Fue precisamente en este agitado y convulsionado escenario en el que se comenzaron a aplicar las iniciativas políticas demócrata cristianas. En el ámbito estrictamente juvenil, las autoridades de gobierno diagnosticaban que los cambios que en esos momentos afectaban a la sociedad industrial habían generado un profundo desconcierto

23 Ibid., pp.5-6.

24 Jorge del Picó: «Perspectivas históricas de la política de juventud», Primer informe nacional de juventud, Instituto Nacional de la Juventud, Santiago, 1994, p.132.

25 Mariana Paz Schkolnik y Luis Eduardo Riquelme: Op. cit., p.7.

26 Una visión crítica del rol de los jóvenes como agentes del cambio político y social se encuentra en el trabajo de Sergio Luzzatto: «Jóvenes rebeldes y revolucionarios (1789-1917)», en Historia de los jóvenes... En él sostiene que el concepto de «juventud revolucionaria» es parte del imaginario político construido a partir del siglo XIX. Ello porque la presencia de la juventud en los acontecimientos políticos de ese siglo es más bien contradictoria. Se sitúa simultáneamente junto a las propuestas más radicales, pero también en la defensa del orden establecido. 
en las unidades familiares y en la sociedad en su conjunto, siendo los niños y los jóvenes los principales afectados. De ahí, entonces, la necesidad de desplegar una política específica, dentro del Plan Nacional de Desarrollo, orientada a integrar a los jóvenes a este mundo en proceso de cambio. Para esos efectos se creó la Oficina de Asesoría en Juventud, la que quedó bajo la responsabilidad del ex dirigente de la FECH, Marco Antonio Roca, y que asumió como tarea específica, el asesorar a la presidencia en aquellas iniciativas que afectaran directamente a los jóvenes ${ }^{27}$

Simultáneamente se creó la Dirección de Educación Extraescolar (1968), dirigida a promocionar el desarrollo de actividades extraescolares tanto de jóvenes adscritos al sistema escolar como con aquellos que se encontraban fuera del mismo. En este caso se apuntaba a la ejecución de actividades que permitieran hacer un buen uso del «tiempo libre» de los jóvenes, previniendo de esta forma su temprana sociabilización en el mundo del alcohol. Ese mismo año (1968) se creó la Oficina Nacional de Servicio Voluntario, a la cual se le entregó la responsabilidad de sistematizar el trabajo solidario de los jóvenes en sus comunidades, adquiriendo especial relevancia las campañas de alfabetización. ${ }^{28}$

A pesar de estos importantes avances es claramente perceptible durante el gobierno de Eduardo Frei Montalva, la ausencia de una estrategia de financiamiento fiscal coherente que diera sustentabilidad de largo plazo a los programas de cambio. Al punto que muchos de ellos sólo quedaban esbozados o eran tempranamente abandonados. Mientras que por otro lado, no es menos evidente que los principales beneficiarios de dichas iniciativas fueron, a la larga, los sectores medios y los trabajadores urbanos asalariados, pero no necesariamente los más pobres. ${ }^{29}$ De la misma manera se puede precisar que durante este período, en materia juvenil, no hubo un proyecto de institucionalización de la política de juventud y no se avanzó sistemáticamente en la planificación y organización de programas dirigidos hacia ese sector. Se trató sólo de una asesoría que operó en función de los requerimientos que la política de «promoción popular» le planteaba a las autoridades. Los jóvenes, en este caso, constituían la punta de lanza de un Estado comprometido con el proceso de modernización de sus 
sectores sociales más atrasados. ${ }^{30}$

De la misma manera durante el gobierno de la Unidad Popular, no es posible advertir la existencia de una política de juventud. Pero no es menos efectivo que se le asignó a los jóvenes un rol estratégico, en cuanto actores y conductores, en el proceso movilizador que debía conducir al socialismo. Sus tareas específicas tenían que ver con las campañas de alfabetización —concientización-, campañas de salud, balnearios populares, etc., que se desplegaban especialmente entre y con pobladores y campesinos. Mirado desde esa perspectiva, en este caso sólo estamos en presencia de una visión más radical del rol que le correspondía a los jóvenes en la política de «promoción popular». ${ }^{31}$

A partir de 1973 el objetivo de las políticas sociales fue la erradicación de la extrema pobreza, a través de una serie de políticas selectivas y focalizadas dirigidas a la franja más pobre de la población. El Estado abandonó su rol «benefactor» y concentró su esfuerzo asistencial en los grupos que no estaban en condiciones de satisfacer por sí mismos sus necesidades más esenciales. Esto obligó a los grupos populares no marginales, a los estratos medios y a los sectores altos, a proveerse por sí solos los servicios sociales que anteriormente obtenían del Estado. De esta manera la distribución de los subsidios estatales comenzó a realizarse de acuerdo a criterios de extrema necesidad y no en función de la capacidad de pago de los beneficiarios. La política social, orientada sobre estos criterios, conllevó el traspaso de muchas responsabilidades públicas al ámbito privado —previsión, educación, salud, etc.- - a la par que se profundizaban las inequidades en la distribución del ingreso. ${ }^{32}$

Para atender los requerimientos del mundo juvenil el régimen militar creó la Secretaría General de la Juventud, la cual intentó cooptar a los jóvenes en torno a los objetivos de refundación nacional que se proponía la dictadura. De esta manera el organismo ejecutor de los programas juveniles de gobierno asumió un rol y un contenido eminentemente político, centrando su esfera de influencia en el activismo: deportes, cultura, desarrollo social, capacitación, etc. El período de mayor desarrollo de este modelo se encuentra entre 1973 y 1982, coincidiendo con la fase de repliegue del movimiento popular. Pero el

$30 \quad$ Jorge del Picó: Op. cit., p.137.

31 Ibid., pp.139-141.

32 Mariana Paz Schkolnik y Luis Eduardo Riquelme: Op. cit., pp.9-10. 
desgaste del régimen y su pérdida de influencia y legitimidad social, especialmente a partir de las protestas populares — protagonizadas mayoritariamente por jóvenes urbano populares-, repercutió en la Secretaría General de la Juventud, la que colapsó como instrumento político a fines de la década de $1980 .{ }^{33}$

Es posible concluir, entonces, que en este período, que se cierra a fines de la década de 1980, los jóvenes sólo son reconocidos en cuanto estudiantes $\mathrm{y}$, a partir de ello, en cuanto constituyen instancias corporativas, como movimiento social. Sólo a partir del fenómeno de las protestas sociales antidictatoriales, los jóvenes emergen en la escena nacional como partícipes y protagonistas, diferenciados, del movimiento social popular urbano. ${ }^{34}$ Es precisamente a partir de estos fenómenos que comienza a perfilarse la política social de juventud. Las carencias, exclusiones y puniciones de que fueron objeto los jóvenes durante el gobierno autoritario y el rol que adquirieron sus movilizaciones en el marco de la lucha por la recuperación de la democracia, los revelaron, de cara a la década de 1990, como sujetos de una política específica orientada a integrarlos al proceso de modernización y democratización de la sociedad y el Estado. De esta manera, el asumir y cancelar la «deuda social con los jóvenes», se convirtió en la orientación y en el eje fundamental sobre el cual debía descansar la política social de juventud en la última década del siglo.

Tal es así que con el arribo al gobierno de la Concertación de Partidos por la Democracia, se adscribió a una política social orientada básicamente a la planificación y gestión de sectores sociales en las áreas de educación, salud, vivienda, etc. y a la atención de determinados grupos objetivos - niños, mujeres, jóvenes-, a objeto de reducir las profundas desigualdades sociales heredadas del régimen dictatorial y, por esta vía, elevar el bienestar de la población, disminuyendo los sectores que vivían en situación de pobreza. ${ }^{35}$ De esta manera el Estado recuperaba su rol interventor en las relaciones civiles, a objeto de proteger a los sectores más vulnerables, en un contexto político que

33 Jorge del Picó: Op. cit., pp.147-151.

$34 \quad$ Al respecto se pueden revisar los trabajos de José Weinstein: Los jóvenes pobladores en las protestas nacionales (1983-1984). Una visión sociopolítica, CIDE, Santiago, 1989; y Los jóvenes pobladores y el Estado, CIDE, Santiago, 1990.

35 Flavio Cortez: «Fundamentos, características e institucionalidad de la política social juvenil en Chile», Primer informe nacional de juventud, Instituto Nacional de la Juventud, Santiago, 1994, p.156. 
reconocía la incapacidad del mercado para cumplir la función de «igualador social». 36

En el nuevo escenario que se inauguraba, los enfoques teóricos que orientaron la definición de política social de juventud fueron heterogéneos. En todo caso predominaron originalmente - y aún continúan haciéndolo - básicamente dos paradigmas. Por una parte la noción de integración social, que descansaba en la percepción de los jóvenes como anómicos; y el enfoque sobre el daño o riesgo psicosocial, que aludía a la condición social que afectaba a un desarrollo sano de la personalidad. ${ }^{37}$ En ambos casos los jóvenes pasaban a convertirse en objetos de políticas remediales y no en sujetos con capacidad de co-construir ciudadanía a partir de su propia realidad social y cultural. ${ }^{38}$ Es precisamente a este nivel donde se explicita la tensión fundamental entre la política social y el mundo juvenil, es decir, la tendencia de los jóvenes de crecer hacia lo que quieren ser-hacer capacidad de producción y autoproducción de identidad- o ser lo que la sociedad quiere que sean - la internalización de los estereotipos y la carencia de posibilidades-. 39

Los objetivos implícitos en la política social juvenil tienden entonces a conformarse en torno a dos ejes, por una parte, ofrecer

36 Oscar Dávila: «Estado y políticas sociales. Del Estado protector al Estado subsidiario», Última Década Nº9, 1998, p. 107.

37 Flavio Cortez: Op. cit., p.159. Vamos a entender por anomia, el quiebre de la estructura cultural que se produce cuando hay una disyunción aguda entre las normas y los objetivos culturales, y las capacidades que se estructuran socialmente en los individuos del grupo para obrar de acuerdo a estos objetivos. Es el rompimiento de los lazos de cohesión social de un grupo, en relación a las conductas normativas que impone la sociedad; María Emilia Tijoux: «Jóvenes pobres en Chile: nadando en la modernidad y la exclusión», Última Década No3, 1995, p.28. El concepto de daño psicosocial pone el acento en los comportamientos juveniles que lo expresan y no en las circunstancias que lo generan, es por ello que incide en la estigmatización de los jóvenes, no atribuyéndoles la capacidad de comprometerse activamente en la transformación de sus situación; José Martínez: «Construcción de identidad juvenil y actualización de la juventud», Primer informe nacional de juventud, p.312.

38 La política pública sólo reconoce a los jóvenes populares como beneficiarios de la intervención estatal; en relación con este punto ver, Oscar Dávila: «Juventud popular: transitando por el trapecio. ¿Con red o sin ella?», Última Década No3, 1995, p.55.

39 Claudio Duarte: Juventud popular. El rollo entre ser lo que queremos o ser lo que nos imponen, Colectivo de Educación Popular Juvenil Newence, Santiago, 1994, pp.43-64. 
oportunidades y brindar recursos para que los jóvenes pudieran prepararse para enfrentar la vida adulta, especialmente en el aprendizaje de los roles que a futuro les tocaría asumir y; por otro lado, generar condiciones para la conformación e integración de la personalidad, de manera de permitirles alcanzar una clara y reconocida identidad social. En función de ello los criterios operativos de la política debían ser básicamente dos: la universalidad, para aquellos servicios que debían ser provistos de manera general y la selectividad, para aquellas necesidades que debían ser atendidas de manera focalizada. ${ }^{40}$

A consecuencia de este enfoque y del diseño consecuente, la política de juventud se explicitó a través del denominado Programa de Oportunidades para los Jóvenes (PROJOVEN), que definió 44 programas en 7 áreas: trabajo, educación, salud, protección y rehabilitación de menores, participación y derechos juveniles, recreación y uso creativo del tiempo libre y vivienda. ${ }^{41}$ Pero este programa, tributario de una concepción agregativa de la política social, tempranamente mostró sus insuficiencias y fracasos, al no impactar adecuadamente entre los jóvenes más pobres y, por lo tanto, al no cumplir con el objetivo de disminuir las brechas sociales. ${ }^{42}$

Este fracaso devela una constante histórica. En Chile las políticas sociales no han sido parte del articulado de una constitución política, es decir, no son parte de la estructura del aparato del Estado. Por el contrario, han surgido como leyes especiales, que operan desde los intersticios de la constitución, bajo la presión de la demanda social. Han sido, por lo tanto, instrumentos de legitimación tardía de un régimen constitucional que no fue legítimo al momento de su construcción. ${ }^{43}$

Es por ello que la política social dirigida a la juventud se orienta, básicamente, a dos cosas: integrarla en la sociedad moderna sobre la base de un modelo cultural hegemónico — civilizarla, desbarbarizarla - y competir en el mercado — productores y consumido-

$40 \quad$ Flavio Cortez: Op. cit., pp.161-163.

41 Instituto Nacional de la Juventud: «PROJOVEN. El programa de oportunidades», Santiago, 1993.

42 Al respecto, Astrid Oyarzún: «Política de juventud. Encuentros y desencuentros», Última Década N², 1994; y Oscar Dávila y Claudio Silva: Políticas de juventud y su expresión en lo local, CIDPA, Viña del Mar, 1999, p.5.

43 Gabriel Salazar: «La educación de la juventud como una educación para el cambio», Última Década №11, 1999, pp.114-115. 
res-. ${ }^{44}$ En consecuencia el énfasis formativo e integrativo se plantea respecto del individuo y no en relación a la colectividad. Lo anterior impide que los jóvenes encuentren canales expeditos de integración. Por el contrario, los diferentes aspectos que quedan involucrados en la política social operan profundizando las desigualdades y las exclusiones. Al respecto cabe agregar, por ejemplo, que la variable que más discrimina hoy día a los sectores juveniles populares es la educación. Así, los jóvenes pertenecientes a las clases sociales más acomodadas reciben una educación de mejor calidad que les garantiza mejores oportunidades y más opciones de inserción social, mientras que los jóvenes de sectores populares al recibir una educación más precaria ven obstaculizadas sus propias opciones y oportunidades de integración. ${ }^{45}$

El problema radica, en gran medida, en que la política social es incapaz de reconocer y asumir la existencia de un colectivo social - los jóvenes - depositario de saberes y quehaceres que lo habilitan como constructor de cultura. Este criterio, propio del tipo de modernización que ha asumido el país, ha provocado un distanciamiento entre el Estado y los jóvenes populares. ${ }^{46}$ Ello porque se ha construido un sistema de poder centralizado que no toma en cuenta las mediaciones entre los centros de poder y la masa de la sociedad civil. ${ }^{47}$ Reconocer, entonces, la condición de los jóvenes como constructores de cultura obligaría a las autoridades a rediseñar la política pública de desarrollo juvenil, asentando sus ejes centrales en la construcción de identidad y en la articulación de proyectos de vida. ${ }^{48}$

44 El carácter coactivo que asume el proceso integración de los jóvenes, puede ser analizado en Juan Carlos Gómez: «La capacitación laboral juvenil: una forma de disciplinamiento social de los pobres. Chile 1991-1994», Documento de Trabajo $\mathrm{N}^{\circ}$ 7, Centro de Investigaciones Sociales, Universidad ARCIS, Santiago, 1996.

45 Oscar Dávila: «Exclusión social y juventud popular», Última Década N8, 1998, p.99.

46 Una manifestación de este fenómeno es el creciente desinterés de los jóvenes por la política formal —elecciones y partidos políticos-; al respecto se puede ver el artículo de Patricio Bustos: «Jóvenes: reflexiones en torno al tema de la participación y la política», Última Década Nº7, 1997.

47 María Emilia Tijoux: Op. cit., p.27.

48 Las identidades juveniles tienden a construirse en ámbitos de sociabilidad cargados de ritualidad. En ellos los jóvenes tienen la oportunidad de «ser» efectivamente jóvenes y encontrarse como tales junto a sus pares. Las dinámicas de sociabilización que despliegan en ellos — solidaridades, afectos, transgresiones, etc.- , tienden a reforzar los sentidos de pertenencia y ad- 
Es necesario, por lo tanto, visualizar a la juventud como un período de la vida que tiene sus propias posibilidades y restricciones, y no entenderla solamente, como un período de moratoria y preparación para el futuro desempeño de roles adultos. Se hace imprescindible, entonces, asumir al joven en su presente concreto, dando relevancia a la actualización de la juventud mediante la satisfacción de las necesidades esenciales — calidad de vida - y la promoción de los derechos juveniles. ${ }^{49}$

Pero hasta el momento las políticas sociales sólo han logrado modernizar la marginalidad, creando centros de consumo - shopings, malls - para jóvenes con empleo precario. Han creado el sentido del consumo, pero no han sido capaces de crear los elementos de infraestructura suficiente como para que esa aspiración al consumo pueda ser adecuadamente satisfecha. Esta contradicción se enfrenta mediante una estrategia combinada de represión e integración parcial. De esta manera las conductas transgresoras o los focos de concentración de jóvenes populares son encuadrados y sistemáticamente hostilizados: represión zonal —arrestos barriales, detención por sospecha- y represión sistemática contra los grupos más conflictivos — subversión, delincuencia-; mientras que los medios de comunicación de masas y las actividades recreativo-culturales operan, respectivamente, domesticando y encapsulando la protesta social; por último, el acceso a un consumo de bajo costo y la capacitación laboral aparecen como la cristalización de la integración para los jóvenes pobres. Partiendo de esa perspectiva es nuestras opinión que la situación de la juventud no ha cambiado, se continúa revolcando en su misma marginalidad, solamente se ha modernizado en su marginalidad. ${ }^{50}$

\section{A MODO DE CONCLUSIÓN}

Los sectores populares se han construido históricamente en los bordes del sistema. Ello ha determinado que, en general, sus relaciones con el Estado se encuentren permanentemente conflictuadas. Su

hesión. En relación con este tema se puede ver el trabajo de Daniel Contreras: «Sujeto juvenil y espacios rituales de identidad: comentarios sobre el caso del carrete», Última Década №5, 1996, pp.161-196. Para el caso europeo, Daniel Febre, da cuenta de circuitos similares en su trabajo «'Forjar la juventud' en el pueblo», en Historia de los jóvenes...

49 José Martínez: Op. cit., pp.309-319.

50 Gabriel Salazar: Op. cit., pp.118-119. 
defensa de la autonomía y de los aspectos esenciales de su identidad social, los han contrapuesto permanentemente con las iniciativas y mecanismos disciplinadores y homogeneizadores desplegados por las clases dominantes y el Estado. Pero la profundización de la democracia política y de la democracia social debiera necesariamente situarnos en un escenario diferente. Efectivamente, es en la preservación de su autonomía e identidad donde se encuentra su potencial de integración.

La autonomía cultural, entendida como los intereses, los saberes y los quehaceres específicos del mundo juvenil, constituye el soporte sobre el cual debe descansar la política de desarrollo de este sector. El devenir de la cultura popular y por ende el de la cultura juvenil, discurre al margen de las instituciones y disposiciones normativas del aparato público. Se trata de un fenómeno que se ha desarrollado históricamente y, por lo tanto, debe ser reconocido en sus particularidades, sin tratar de intervenirlo ni de descalificarlo. Al respecto Astrid Oyarzún sostiene que,

Los jóvenes buscan ser reconocidos en los espacios que supuestamente abre la democracia para todos sus ciudadanos. Buscan que se les respeten sus formas de hablar, vestir, comportarse, sus opciones políticas, de credo y de sexo. Pues vivir en democracia para ellos significa no solamente poder acceder a un mayor grado de cultura (la que no es cuantificable), sino ser reconocidos como tales dentro del espectro de posibilidades que se abren en el nuevo contexto. La cultura, en ese sentido, no puede definirse como una e invariable. ${ }^{51}$

Ahora bien, si reconocemos la autonomía de la cultura juvenil podemos entonces asumir que los jóvenes en cuanto movimiento social son capaces y tienen las potencialidades para desarrollar su propio concepto y su propia forma de entender la ciudadanía. ${ }^{52}$ Ello normalmente tiende a alejarlos de la política social la cual es percibida como clientelizadora.

51 Astrid Oyarzún: «El modo urbano y moderno de vivir la experiencia juvenil», Última Década Nº1, 1993, p.93.

52 A contrapelo de lo que sostiene Eduardo Valenzuela - «¿Movimiento juvenil en la transición?», en Cristian Parker y Pablo Salvat (compiladores), Formación cívico-política de la juventud. Desafío para la democracia, CERC, Universidad Academia de Humanismo Cristiano, Producciones del Ornitorrinco, Santiago, 1992—, los jóvenes se constituyen socialmente en torno a los ámbitos específicos que le permiten recrear y construir cultura — el entramado local—, adquiriendo su relación con el Estado una dimensión estrictamente funcional. 
Hoy día existe una condición de ser joven que se puede visualizar no sólo en los estigmas, discriminaciones, exclusiones y carencias de que son víctimas los jóvenes. También existe una asociatividad juvenil, heterogénea, diversa, que va desde el grupo cultural hasta la barra brava, pasando por un sinnúmero de otras experiencias: talleres de zanco, tribus urbanas, juventudes políticas, grupos cristianos, etc., que practican formas de sociabilidad, y por ende formas de cultura, propiamente juveniles. ${ }^{53}$ Estos lazos micro-asociativos a nivel barrial o local vienen a constituir el nivel más primario de la organización, la que si bien tiende a ser informal, inestable e incluso pasajera, devela el carácter comunitario de la cultura juvenil. De esta manera la marginalidad se vuelve energía expresiva, acción social y, eventualmente, se transforma en movimiento. ${ }^{54}$ La resistencia a la cooptación se manifiesta como una expresión cultural de rechazo a las estructuras y mecanismos de dominación que impone el sistema. Esta resistencia se nutre del quehacer y de las contradicciones cotidianas que atraviesan al mundo juvenil y se manifiesta en la generación de alternativas contraculturales - fuerza transformadora - surgidas desde el seno del mismo del mundo juvenil. 55

Corresponde entonces reconocer que en otras épocas los proyectos juveniles de vida se definían rápida y regularmente, en función de la adscripción laboral y social propuesta por el mundo de los adultos. Efectivamente, las relaciones padres-hijos se construyeron históricamente en torno a la formalización y el disciplinamiento. Los moldes de anteposición y subordinación, de mando y obediencia, constituyeron la base sobre la cual se edificó la cultura patriarcal. ${ }^{56}$ Era ella precisamente la que definía tempranamente los roles a desarrollar con posteridad por los jóvenes populares: obreros y domésticas intramuros o extramuros-.

Como señalamos previamente, la ampliación de la oferta educativa, desde mediados de la década de 1960, trasladó este rol decisorio respecto de los proyectos de vida juveniles —encubierto bajo el

53 Enrique Martín Criado, sostiene que las subculturas juveniles son subculturas de clase, cuyos conflictos (de clase, generacionales, etc.), no son otra cosa que conflictos de poder en el marco de procesos específicos de reproducción social; en Producir la juventud, Istmo, Madrid, 1998, pp.31ss.

54 María Emilia Tijoux: Op. cit., p.40.

55 Claudio Duarte: Op. cit., pp.44-50.

56 Norbert Elías: «La civilización de los padres», en La civilización de los padres y otros ensayos, Norma, Santafé de Bogotá, 1998, pp.449-450. 
rótulo de orientador- desde el ámbito de la familia patriarcal hacia el ámbito de la escuela y el liceo, en el marco de una sociedad en la cual el Estado comenzaba a jugar funciones protagónicas en el conjunto del quehacer social. Pero hoy día, frente a la pérdida de legitimidad del Estado como agente de cambio y particularmente desde la perspectiva del colapso de su función de "promoción social» por la vía de la educación, la capacidad de definir el proyecto de vida ha sido restituida al sujeto juvenil. ${ }^{57}$ Se trata, en todo caso de una «autonomía relativa», ${ }^{58}$ sujeta a las presiones y compulsiones de una sociedad cada vez más explotadora, segmentada, excluyente y estigmatizadora; pero en la cual, y pese a todo, el sujeto juvenil aparece instalado, definitivamente, con cultura propia y, a partir de ello, con la posibilidad de recrear proyectos propios.

Pese a que los jóvenes han sido asumidos como un desecho de la política liberal, pese a las políticas sociales de retaguardia que se han diseñado para integrarlos, los jóvenes han jugado un rol histórico al rebelarse, protestar y pelear por el cambio. ${ }^{59}$ Los cambios sociales y políticos operados históricamente: la independencia nacional, las revoluciones de 1841 y 1851, la constitución del movimiento popular a comienzos del siglo XIX, la radicalización político social del período 1967-1973 y las protestas populares de la década de 1980, no fueron protagonizadas por generaciones de viejos, ellos coparon el poder: los protagonistas fueron los jóvenes.

VIÑA DEL MAR, DICIEMBRE DE 1999

$57 \quad$ Sobre los crecientes niveles de autonomía de que disponen los jóvenes para definir sus proyectos de vida, ver Michaela Weyand: «Sobre la realidad de la vida cotidiana de los jóvenes en poblaciones en el nuevo orden democrático: ‘ni tan protagonista ni tan víctima’», Última Década Nº1, 1993.

58 El concepto de «autonomía relativa» está tomado de Gabriel Salazar: «Del proyecto histórico de los pobres: autonomía relativa y autoeducación», Proposiciones $\mathrm{N}^{\circ} 15,1987$.

59 Gabriel Salazar: «La educación de la juventud...», pp.119-120. 